\title{
Human Adrenocorticotropin-Secreting Pituitary Adenomas Show Frequent Loss of Heterozygosity at the Glucocorticoid Receptor Gene Locus*
}

\author{
NANNETTE A. T. M. HUIZENGA, PIETER DE LANGE, JAN W. KOPER, \\ RICHARD N. CLAYTON, WILLIAM E. FARRELL, AART JAN VAN DER LELY, \\ ALBERT O. BRINKMANN, FRANK H. DE JONG, AND STEVEN W. J. LAMBERTS \\ Departments of Internal Medicine III (N.A.T.M.H., P.d.L., J.W.K., A.J.v.d.L., F.H.d.J., S.W.J.L.) and \\ Endocrinology and Reproduction (A.O.B.), Erasmus University Rotterdam, 3015 GD Rotterdam, The \\ Netherlands; and the Department of Medicine, Keele University (R.N.C., W.E.F.), Stoke on Trent, \\ ST4 7QB United Kingdom
}

\begin{abstract}
Corticotropinomas are characterized by a relative resistance to the negative feedback action of cortisol on ACTH secretion. In this respect there is a similarity with the clinical syndrome of cortisol resistance. As cortisol resistance can be caused by genetic abnormalities in the glucocorticoid receptor (GR) gene, we investigated whether the insensitivity of corticotropinomas to cortisol is also caused by de novo mutations in the GR gene.

We screened for the GR gene in leukocyte and tumor DNA from 22 patients with Cushing's disease for mutations using PCR/single strand conformation polymorphism analysis. In a previous study, we identified 5 polymorphisms in the GR gene in a normal population. These polymorphisms were used as markers for the possible occurrence of loss of heterozygosity $(\mathrm{LOH})$ at the GR gene locus.

Except for 1 silent point mutation, we did not identify novel mutations in the GR gene in leukocytes or corticotropinomas from these patients. Of the 22 patients, 18 were heterozygous for at least 1 of the
\end{abstract}

polymorphisms. In 6 of these patients, LOH had occurred in the tumor DNA. Of 21 patients examined for LOH on chromosome 11q13, only 1 , with a corticotroph carcinoma, showed allelic deletion. As controls we studied 28 pituitary tumors of other subtypes (11 clinically nonfunctioning, 8 prolactinomas, and $9 \mathrm{GH}$-producing adenomas) and found evidence for $\mathrm{LOH}$ in only 1 prolactinoma.

In six patients LOH was found at the GR gene locus (chromosome 5 ) in DNA derived from adenoma cells. Our observations indicate for the first time that $\mathrm{LOH}$ at the GR gene locus is a relatively frequent phenomenon in pituitary adenomas of patients with Cushing's disease. This might explain the relative resistance of the adenoma cells to the inhibitory feedback action of cortisol on ACTH secretion. The specificity of the GR LOH to corticotropinomas supports this concept. Somatic mutations of the GR are not a frequent cause of relative cortisol resistance in these cells. (J Clin Endocrinol Metab 83: 917921, 1998)
$\mathrm{C}$ USHING'S disease is caused by an ACTH-secreting pituitary adenoma arising from corticotropic cells. The adenomas are characterized by a relative resistance of the tumor cells to the feedback inhibition by glucocorticoids (GCs) on ACTH secretion $(1,2)$. The biological effects of cortisol (and other GCs) are mediated by the glucocorticoid receptor (GR), a member of the family of intracellular hormone receptors (3). These receptors are characterized by a three-domain structure: a carboxyl-terminal ligand-binding domain with transcriptional activity, a central DNA-binding domain, and an N-terminal domain essential for transcription activation (3). The effects of GCs can be the result of either DNA binding of the ligand-bound receptor or interactions of the receptor with other proteins within the nucleus (4). Mutations in the hormone-binding domain of the GR gene have been described as the cause of familial glucocorticoid resistance (5-8). In a recent study, Karl and co-workers (9) screened the GR gene in patients who developed Nelson's

Received July 8, 1997. Revision received November 7, 1997. Accepted November 13, 1997.

Address all correspondence and requests for reprints to: Dr. Nannette Huizenga, Dijkzigt University Hospital, Room Bd 277, Dr. Molewaterplein 40, 3015 GD Rotterdam, The Netherlands.

* This work was supported by a grant from the Dutch Organization for Scientific Research. syndrome after bilateral adrenalectomy for Cushing's disease and found a heterozygous somatic frame-shift mutation in one of four macroadenomas investigated.

In the present study, we analyzed the GR gene in leukocyte and tumor DNA samples from 22 patients with Cushing's disease, using PCR/single strand conformation polymorphism (SSCP) analysis, to see whether somatic mutations in the GR gene in tumor DNA were responsible for the relative cortisol resistance of the corticotropic tumor cells. In a previous study (10), PCR/SSCP screening revealed 5 GR polymorphisms in a normal population. Sequence analysis led to the disclosure of point mutations in the PCR fragments containing exons II, IV, V, and IX, respectively. In two of these polymorphisms (summarized in Table 1), the variant sequences occur with relatively high frequencies (exon $\mathrm{V}$ in $31.3 \%$ and exon IX in $13.7 \%$ of the investigated population). This allowed us to use these polymorphisms as markers for the possible occurrence of loss of heterozygosity (LOH) at the GR gene locus. The patients investigated were a subgroup of the patients studied by Buckley et al. (11), who were tested for accumulation of p53. As there are reports that the multiple endocrine neoplasm-1 locus on chromosome $11 \mathrm{q} 13$ is potentially involved in the pathogenesis of all types of pituitary adenoma (12), we also examined this region of the 
TABLE 1. Sex, age, tumor grading, possible loss of heterozygosity at the GR gene locus or chromosomes 9 and 11 , and P53 staining in corticotropinomas from 22 patients with pituitary-dependent Cushing's disease

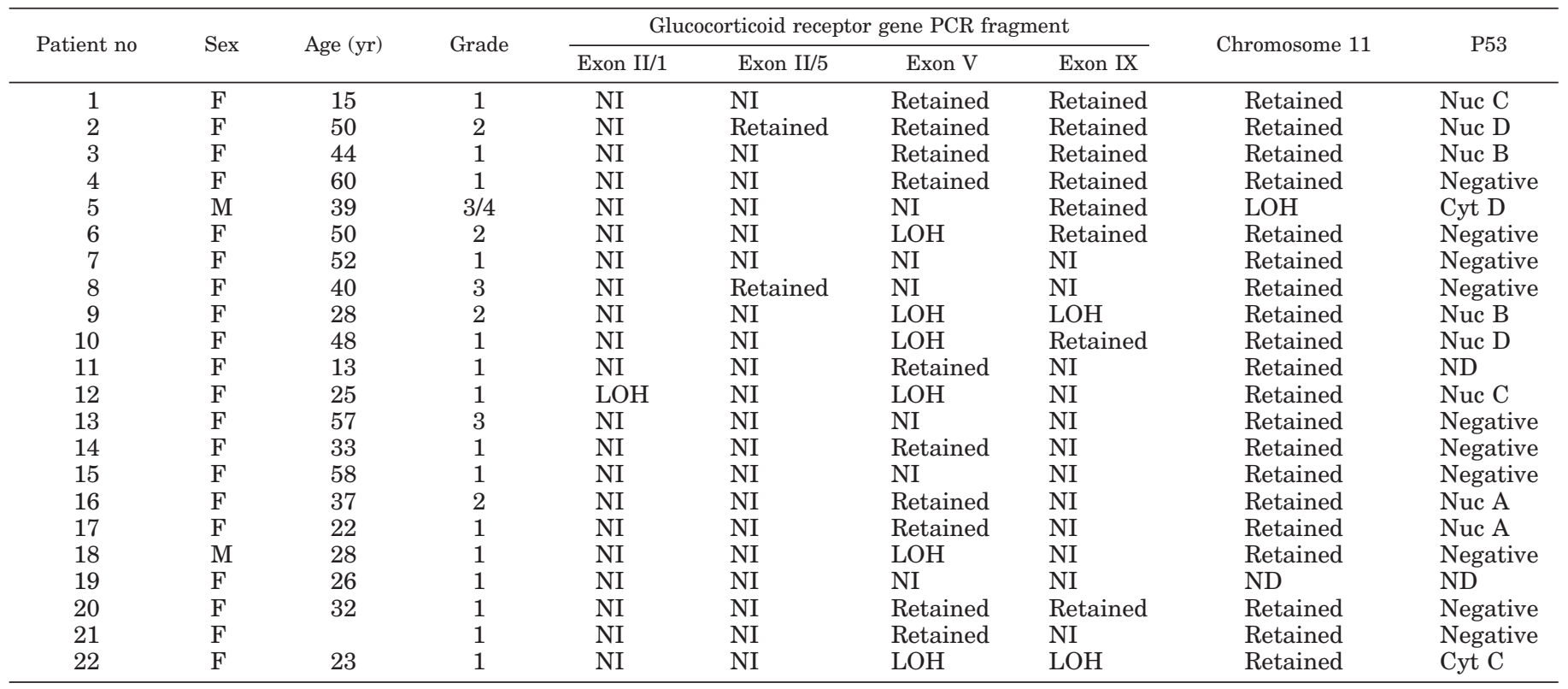

Grade: 1, Microadenoma; 2, macroadenoma, no invasion; 3, macroadenoma with invasion; 4, macroadenoma with intra/extracranial spread. $\mathrm{LOH}$, Loss of heterozygosity; NI, not informative; ND, not determined; retained, informative, no LOH. P53: Nuc, nuclear staining; Cyt, cytoplasmic staining; A, 75-100\%; B, 50-75\%; C, 25-50\%; D, <25\%

genome for $\mathrm{LOH}$ in this unselected cohort of corticotropinomas (13).

\section{Subjects and Methods}

All 22 patients included in the study had clinical features of Cushing's syndrome and biochemical evidence of excessive cortisol production. All failed to suppress with low dose (4 doses of $0.5 \mathrm{mg}$ ) dexamethasone. With regard to the differential diagnosis, different definitions of suppression with high dose (4 doses of $2 \mathrm{mg}$ ) dexamethasone suppression tests were used (e.g. 17-hydroxycorticosteroid, urinary free cortisol, and sometimes plasma cortisol values). The high dose dexamethasone test does not allow us to distinguish precisely the sensitivity to dexamethasone among this group of 22 patients with histologically proven ACTHsecreting pituitary adenomas.

Using PCR/SSCP we analyzed the GR gene in tumor and leukocyte DNA samples from 22 patients with pituitary-dependent Cushing's syndrome due to surgically and histologically defined adenomas. All patients were operated on by transsphenoidal selective adenomectomy. Tumor samples were fixed in $10 \%$ formalin and embedded in paraffin. Tumor DNA was extracted from slide material using standard methods (13), with the benefit that the DNA originates from histologically defined adenoma tissue and, therefore, is as homogeneous as possible. Leukocyte DNA was extracted from peripheral leukocytes using standard methods. Tumors were divided into categories according to invasiveness, based on the patients' computed tomography and magnetic resonance imaging reports, as described by Bates et al. $(13,14)$. Grades 1 and 2 include microadenomas and macroadenomas without radiological evidence of invasion, respectively. Grade 3 are macroadenomas with local invasion. One patient (no. 5) was previously described (15). She had a corticotropic carcinoma, with intracerebral metastases demonstrated on magnetic resonance imaging scan and at autopsy (grade 4).

To investigate the specificity of the changes in the GR gene in corticotropinomas, we also studied 28 other pituitary adenomas (11 clinically nonfunctioning, 8 prolactinomas, and $9 \mathrm{GH}$-secreting adenomas).

\section{PCR/SSCP analysis of the GR gene}

PCR amplification of the GR gene was carried out using primers previously described by Koper et al. (10). Because of the very limited quantity of DNA in the samples, PCR amplification was performed in two steps. The first amplification was performed in a total volume of 20 $\mu \mathrm{L}$ containing leukocyte or tumor DNA solution, 6 pmol of each oligonucleotide from four different primer pairs, $200 \mu \mathrm{mol} / \mathrm{L}$ of each deoxy-NTP, $3 \mathrm{mmol} / \mathrm{L} \mathrm{MgCl}_{2}$, $0.5 \mathrm{U}$ AmpliTaq (Perkin-Elmer, Norwalk, CT), $50 \mathrm{mmol} / \mathrm{L} \mathrm{KCl}$, and $10 \mathrm{mmol} / \mathrm{L}$ Tris (pH 8.3). A 1:300 dilution of the primary PCR product was used as a template for a second PCR amplification under the same conditions, using one primer pair in each reaction. SSCP analysis of the PCR products was carried out using $0.5 \times$ mutation detection enhancement (MDE) polyacrylamide gels (J. T. Baker Chemicals, Deventer, The Netherlands) in the presence or absence of 5\% glycerol at $4 \mathrm{C}$ as described by Orita et al. (16). Each SSCP gel contained samples from controls with the normal sequence and from controls with each of the five GR gene polymorphisms previously described by Koper et al. (10). DNA fragments displaying an abnormal migration pattern during SSCP analysis were amplified with the same primers for direct sequencing using a modified Sanger dideoxynucleotide chain termination method, described in detail by Karl et al. (7).

\section{LOH on chromosome 11}

PCR amplification was performed using primers spanning the microsatellite repeat at the PYGM locus (11q13). Primer sequences for the amplification were 5'-GGAATGCTGATTTCCAGGTT-3', and 5'-CTGTCAGGTAGCAACTGACATC- $3^{\prime}$, respectively. PCR reaction conditions were: primer annealing at $50-54 \mathrm{C}$ for $2 \mathrm{~min}$, primer extension at $72 \mathrm{C}$ for $2 \mathrm{~min}$, denaturation at $94 \mathrm{C}$ for $1 \mathrm{~min}$, and final extension at $72 \mathrm{C}$ for $5 \mathrm{~min}$. Leukocyte and tumor PCR products were run adjacently on $8-10 \%$ nondenaturing polyacrylamide gels, fixed in 10\% methanol- $10 \%$ acetic acid, and then incubated in $0.1 \%$ aqueous silver nitrate for $15 \mathrm{~min}$. After two brief washes in distilled water, products were visualized by development in an aqueous solution of $1.5 \%$ sodium hydroxide and $0.1 \%$ formaldehyde. Allelic loss is identified by a reduction in intensity of more than $80 \%$ or the absence of one of the expected PCR products (13). Results were reviewed independently by two observers, and allelic deletion was only recorded if agreed upon by both. All samples in which $\mathrm{LOH}$ was identified underwent repeat PCR amplification and gel electrophoresis with identical results. 


\section{Results}

Age, sex, and tumor grading of the 22 patients investigated are shown in Table 1 . There were 20 female and 2 male patients, aged 13-58 yr. There were 3 invasive tumors, 4 macroadenomas without invasion, and 15 microadenomas. Patient 18 showed a novel SSCP pattern in exon VI of both tumor and leukocyte DNA. Direct sequence analysis showed that the abnormal pattern was the result of a silent heterozygous point mutation (GCA to GCG at codon 618, both coding for an alanine in the receptor protein; data not shown). None of the other DNA samples analyzed revealed novel SSCP variants in the GR gene. The GR PCR fragments containing the polymorphisms, as described previously (10), served as markers for possible $\mathrm{LOH}$ in the present study. The polymorphism in the PCR fragment containing exon IV was not present in these 22 patients. In 1 patient (no. 12), the polymorphism in PCR fragment exon II/1 was present in leukocyte DNA. In the tumor DNA of this patient, however, the polymorphism was absent. This suggests that in the tumor the variant allele was lost (Table 1 ). The polymorphism in the 3 '-part of exon II (PCR fragment exon II/5) was present in 2 subjects (no. 2 and 8). The polymorphism was seen in both leukocyte and tumor DNA, indicating that there was no $\mathrm{LOH}$ in this part of the GR gene in these two subjects (Table 1).

Figure 1 shows the SSCP patterns of the polymorphism in the PCR fragment containing exon $\mathrm{V}$ in controls (AA, homozygous for the normal allele; $\mathrm{AB}$, heterozygous; $\mathrm{BB}$, homozygous for the variant allele), together with the leukocyte and tumor SSCP patterns from several patients. Taking patient 6 as an example, a difference in the SSCP pattern in leukocyte and tumor PCR products from this patient was observed. Leukocyte DNA showed pattern AB (heterozygous), whereas tumor DNA revealed pattern AA, suggesting that the variant allele was not present in the tumor. A total of 16 patients showed SSCP pattern AB in leukocyte DNA, 6 of whom had an AA pattern in their tumor DNA, indicating that in 6 of the 16 patients who were heterozygous for the polymorphism in exon $\mathrm{V}, \mathrm{LOH}$ occurred at this specific part of the GR. Six other patients were homozygous in leukocyte DNA (5 of them showed pattern AA and 1 showed pattern $\mathrm{BB})$, so the polymorphism was not informative in these patients with respect to LOH (Table 1).

With respect to PCR fragment exon IX, 10 patients were heterozygous for the polymorphism $(\mathrm{AB})$ in leukocyte DNA, 2 of whom showed $\mathrm{LOH}$ in the tumor (SSCP pattern AA; Table 1). The 12 other patients showed the homozygously normal pattern (AA) in leukocyte DNA, so a conclusion

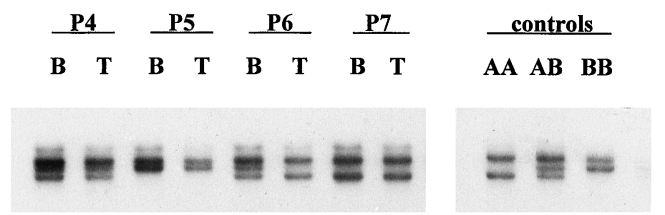

FIG. 1. SSCP patterns of the polymorphism in the PCR fragment containing exon $\mathrm{V}$ in controls (AA, homozygous for the normal allele; $\mathrm{AB}$, heterozygous; $\mathrm{BB}$, homozygous for the variant allele) together with the leukocyte and tumor SSCP patterns from several patients. $\mathrm{P} 6$ revealed pattern AA in the tumor DNA, which in this case represents the presence of one A allele. about a possible $\mathrm{LOH}$ in this part of the GR gene could not be reached in these patients.

It can be concluded that 6 patients show $\mathrm{LOH}$ at the GR locus, 3 of them in PCR fragment of exon V (patients 6, 10, and 18) and 2 of them in both exons V and IX (patients 9 and 22). Patient 12 shows $\mathrm{LOH}$ at the N-terminus of exon II and at exon V. Overall LOH was identified in 6 patients, heterozygosity was maintained in 12 patients insofar as the polymorphisms were informative in these patients, and 4 patients were completely uninformative.

Tumor grading in patients in whose tumor LOH for the GR gene was found, showed that none of these tumors was invasive (Table 1). Only one patient (no. 5) showed LOH on chromosome 11 at the PYGM locus. This subject had a malignant corticotroph carcinoma and has been reported in detail previously (14). All other Cushing's adenomas examined $(n=21)$ retained the PYGM allele at 11q13. Insofar as the data on $\mathrm{LOH}$ were informative, tumors showing $\mathrm{LOH}$ for the GR gene locus do not show LOH on chromosome 11. Similarly, for chromosome $11 \mathrm{LOH}$, heterozygosity in the informative parts of the GR gene was retained.

Of 11 clinically nonfunctioning pituitary adenomas, 6 were heterozygous for the polymorphism in exon $\mathrm{V}$ (showing the $\mathrm{AB}$ phenotype); none of these tumors showed LOH. Five were heterozygous for the polymorphism in exon IX, 4 of which also were heterozygous for the exon $\mathrm{V}$ polymorphism. The tumors exhibited no LOH for exon IX. The polymorphisms II/I and II/5 were not present in the DNA from leukocytes and the adenomas.

Of eight prolactinomas, three were heterozygous for the polymorphism in exon $\mathrm{V}$; one of these tumors showed $\mathrm{LOH}$ (the $\mathrm{AB}$ pattern was changed into a $\mathrm{BB}$ pattern). Two of these tumors were also heterozygous for the exon IX polymorphism without showing LOH. The II/I and II/5 polymorphisms were not present in the DNA from leukocytes and the adenomas. Of nine GH-producing adenomas, two were heterozygous for the exon V and IX polymorphisms but showed no $\mathrm{LOH}$ in the tumor, and one was heterozygous for the polymorphism in exon IX without showing LOH. No II/1 polymorphisms were present in the DNA from leukocytes and the adenomas; in one case the II/5 polymorphism was present in the leukocyte DNA and remained present in the adenoma DNA.

In conclusion, 23 of these 28 pituitary tumor types were heterozygous for at least 1 of the polymorphisms investigated, whereas LOH was detected only in 1 of them. Statistical analysis using the Fisher exact test on LOH in the GR gene in corticotropinomas vs. pituitary adenomas of other origin showed $P<0.02$.

\section{Discussion}

Hypercortisolism in Cushing's disease is caused by semiautonomous ACTH secretion by a pituitary corticotropinoma, in most cases a microadenoma (17). Corticotropinomas are characterized by a decreased sensitivity of the tumor cells to the negative feedback action of cortisol on ACTH secretion $(1,2)$, which is mediated by the GR. Hormonebound GRs regulate the expression of glucocorticoid-responsive genes by activating or repressing the transcription of 
glucocorticoid-regulated genes by binding to positive and negative glucocorticoid response elements (18). The POMC gene has been shown to contain a negative glucocorticoid response element.

With respect to the diminished sensitivity to the inhibitory feedback action of cortisol, corticotropinomas show similarity with the syndrome of cortisol resistance. This syndrome is characterized by increased serum concentrations of cortisol due to a decreased inhibitory feedback by cortisol on pituitary ACTH production without the clinical stigmata of Cushing's syndrome. The increased ACTH production results in secondary overproduction of adrenal androgens and mineralocorticoids (19). It has been demonstrated that mutations in the hormone-binding domain of the GR gene result in the syndrome of cortisol resistance in man (5-8). In the present study we investigated by PCR/SSCP analysis whether somatic mutations in the GR gene in ACTH-secreting pituitary adenoma cells might be responsible for the relative cortisol resistance observed in these tumors. In only one patient (no. 18) was a silent point mutation in exon VI identified (in both leukocyte and tumor DNA), indicating that small de novo mutations in the GR gene in corticotropic cells are not frequently involved in the relative cortisol resistance of ACTH-secreting tumor cells in the pituitary. In a recent paper also no point mutations in the GR gene were found in 17 corticotropinomas, whereas additional studies did not point to a differential relative expression of the two GR isoforms (20).

We have recently described 5 polymorphisms in the GR gene (10). These polymorphisms were used as markers for the detection of $\mathrm{LOH}$ at the GR locus in these 22 corticotropinomas. We found $\mathrm{LOH}$ in 6 of the 18 tumors in which at least 1 of the polymorphisms was informative. In 4 cases, no informative polymorphisms were present. Our data indicate that the deletions that have occurred may be relatively small. Thus, in tumors 6 and 10, LOH was found with respect to exon $\mathrm{V}$, whereas for exon IX, heterozygosity was retained. Moreover, in patient $18, \mathrm{LOH}$ in the tumor was found in exon $\mathrm{V}$, whereas the silent point mutation in exon VI was present in both leukocyte and tumor DNA. For an adequate GC response, all parts of the GR are essential. Deletions such as those observed here will undoubtedly inactivate the gene product if, indeed, any is made. Moreover, GR sensitivity has been shown to be gene dosage dependent. Thus, Karl et al. (7) described a family in which inactivation of 1 copy of the GR gene, through a splice site mutation, resulted in reduced GR number and glucocorticoid resistance. As the present polymorphisms are located within the gene itself, and observations, such as in tumors 6,10 , and 18 , suggest that deletions might be relatively small, it is unlikely that these results could have been reached using extragenic microsatellite markers. LOH of the GR gene was found in 6 of the 18 informative corticotropinomas studied and in only 1 of the 23 informative nonfunctioning adenomas, prolactinomas, and somatotropinomas. This does imply some specificity of this $\mathrm{LOH}$ to corticotropinomas, making it more likely that it contributes to the glucocorticoid resistance of this state.

From the data we obtained to date, it seems that adenomas showing $\mathrm{LOH}$ at the GR gene locus are noninvasive tumors that show no LOH on chromosome 11q13. Although this was the only allele examined, the finding that the most frequent allelic deletion in pituitary adenomas $(12,13)$ was not detected here further supports the tumor subtype specificity of GR LOH in corticotropinomas.

It would have been interesting to determine whether the observed LOH at the GR gene locus is paralleled by reductions in the levels of GR messenger ribonucleic acid and GR protein. Unfortunately, the nature (paraffin-embedded tissues) and quantity of the material make extensive quantitative studies at the protein and messenger ribonucleic acid level impossible. Other studies have demonstrated that homozygous point mutations in the hormone-binding domain of the GR gene cause the clinical syndrome of generalized cortisol resistance in man $(5,6)$. The present data as well as the results from these previous studies suggest that there might be a decreased GR function in the pituitary tumors from the six patients in whom LOH was demonstrated. Consequently, these cells are relatively resistant to the inhibitory feedback action of cortisol on ACTH secretion, which might explain the increased ACTH production by these tumors.

Hypothesizing on the basis of the present data, the following model can be put forward. In a differentiated corticotropic pituitary cell, a spontaneous genetic alteration, $\mathrm{LOH}$ at the GR locus, occurs. Consequently, this cell is relatively insensitive to cortisol. As the mutated corticotropic cell is less sensitive to cortisol, this could be seen as a relative shortage of inhibitory hormones, and it provides an advantage for clonal selection, as previously proposed by Karl et al. (8). A striking example of the enormous clonal expansion due to discontinuation of the physiological inhibitory feedback by cortisol is the Nelson tumor, which is an aggressive, fast growing, ACTH-secreting pituitary adenoma. Nelson tumors appear in $10-30 \%$ of patients who have previously undergone bilateral adrenalectomy for Cushing's disease. In a recent study by Karl et al. (9), a somatic frame-shift mutation in the GR gene was found in one of four Nelson tumors investigated. It was concluded that the GR defect might have played a pathophysiological role in the tumorigenesis of this corticotropinoma. Another example in favor of the theory that clonal expansion of a single genetically altered corticotropic cell occurs as a result of diminished negative feedback by cortisol is given by a patient described by Karl et al. (8). This patient had cortisol resistance due to a dominant negative GR gene mutation. During the treatment for cortisol resistance with low doses of dexamethasone, the patient developed signs and symptoms of Cushing's disease. Despite discontinuation of the dexamethasone treatment, the symptoms of Cushing's disease progressed. Eventually, the patient underwent bilateral adrenalectomy, and subsequently, when a pituitary magnetic resonance scan became positive for a tumor, a corticotropinoma was removed. It was suggested that in this patient the exposure of the corticotroph to enhance stimulation by increased production of hypothalamic CRH and arginine vasopressin or a decreased sensitivity of the corticotroph to the negative feedback by cortisol may have led to adenoma formation.

From the data presented here it can be concluded that simple somatic point mutations in the GR gene in corticotropinomas do not seem to be the cause of the relative cortisol resistance in these tumor cells. However, we demonstrate for 
the first time that there is a frequent loss of heterozygosity at the GR gene locus in ACTH-secreting pituitary adenomas. As deletion of (part of) the GR gene leads to glucocorticoid resistance, this is a possible explanation for their relative resistance to the inhibitory feedback of cortisol on ACTH secretion. Furthermore, LOH at the GR gene locus may play a pathophysiological role in the initiation of corticotropinoma formation, although our data are insufficient to relate this to the size of the tumor.

\section{References}

1. Liddle GW. 1960 Tests of pituitary-adrenal suppressibility in the diagnosis of Cushing's syndrome. J Clin Enocrinol Metab. 20:1539-1560.

2. James VHT, Landon J, Wynn V. 1965 Oral and intravenous suppression tests in the diagnosis of Cushing's syndrome. J Clin Endocrinol Metab. 33:515-524.

3. Giguere V, Hollenberg SM, Rosenfeld MG, Evans RM. 1986 Functional domains of the human glucocorticoid receptor. Cell. 46:645-652.

4. Wright AP, Zilliacus J, McEwan IJ, et al. 1993 Structure and function of the glucocorticoid receptor [Review]. J Steroid Biochem Mol Biol. 47:11-19.

5. Hurley DM, Accili D, Stratakis CA, et al. 1991 Point mutation causing a single amino acid substitution in the hormone binding domain of the glucocorticoid receptor in familial glucocorticoid resistance. J Clin Invest. 87:680-686.

6. Malchoff DM, Brufsky A, Reardon G, et al. 1993 A mutation of the glucocorticoid receptor in primary cortisol resistance. J Clin Invest. 91:1918-1925.

7. Karl M, Lamberts SW, Detera-Wadleigh SD, et al. 1993 Familial glucocorticoid resistance caused by a splice site deletion in the human glucocorticoid receptor gene. J Clin Endocrinol Metab. 76:683-689.

8. Karl M, Lamberts SWJ, Koper JW, et al. 1996 Cushing's disease preceded by generalized glucocorticoid resistance: clinical consequences of a novel, dominant-negative glucocorticoid receptor mutation. Proc Assoc Am Physicians. 108:296-307.

9. Karl M, Von Wichert G, Kempter E, et al. 1996 Nelson's syndrome associated with a somatic frame shift mutation in the glucocorticoid receptor gene. J Clin Endocrinol Metab. 81:124-129.

10. Koper JW, Stolk RP, de Lange P, et al. 1977 Lack of association between five polymrphisms in the glucocorticoid receptor gene and glucocorticoid resistance. Hum Genet. 99:663-668.

11. Buckley N, Bates AS, Broome JC, et al. 1994 p53 Protein accumulates in Cushing's adenomas and invasive non-functional adenomas [corrected and republished in J Clin Endocrinol Metab 1995 Feb;80 (2):4 p following 692]. J Clin Endocrinol Metab. 79:1513-1516.

12. Boggild MD, Jenkinson S, Pistorello M, et al. 1994 Molecular genetic studies of sporadic pituitary tumors. J Clin Endocrinol Metab. 78:387-392.

13. Bates AS, Farrell WE, Bicknell EJ, et al. 1997 Allelic deletion in pituitary adenomas reflects aggressive biological activity and has potential value as a prognostic marker. J Clin Endocrinol Metab. 82:818-824.

14. Burke CW, Adams CBT, Esiri MM, et al. 1990 Transsphenoidal surgery for Cushing's disease: does what is removed determine the endocrine outcome? Clin Endocrinol (Oxf). 33:525-537.

15. Pearce SHS, Trump D, Wooding C, et al. 1996 Loss of heterozygosity studies at the retinoblastoma and breast cancer susceptibility (BRCA2) loci in pituitary, parathyroid, pancreatic and carcinoid tumours. Clin Endocrinol (Oxf). 45:195-200.

16. Orita M, Iwahara H, Kanazawa H, Hayashi K, Sekiya T. 1989 Detection of polymofphisms of human DNA by gel electroforesis as single strand conformation. Proc Natl Acad Sci USA. 86:2766-2770.

17. Krieger DT. 1983 Physiopathology of Cushing's disease. Endocr Rev. 4:22-43.

18. Drouin J, Trifiro MA, Plante RK, Nemer M, Eriksson P, Wrange O. 1989 Glucocorticoid receptor binding to a specific DNA sequence is required for hormone-dependent repression of pro-opiomelanocortin gene transcription. Mol Cell Biol. 9:5305-5314.

19. Lamberts SW, Koper JW, Biemond P, den Holder FH, de Jong FH. 1992 Cortisol receptor resistance: the variability of its clinical presentation and response to treatment. J Clin Endocrinol Metab. 74:313-321.

20. Dahia PL, Honegger J, Reincke M, et al. 1997 Expression of glucocorticoid receptor gene isoforms in corticotropin-secreting tumors. J Clin Endocrinol Metab. 82:1088-1093. 